\title{
An Introduction to Cost and Production Functions
}




\section{ALSO BY DAVID F. HEATHFIELD}

The Econometric Study of the $U K$ (editor)

Production Functions

Topics in Applied Macroeconomics (editor)

The Economics of Co-determination (editor)

Perspectives on Inflation: Models and Policy (editor) 


\section{AN INTRODUCTION TO COST AND PRODUCTION FUNCTIONS}

David F. Heathfield and

Sören Wibe

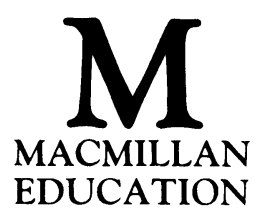


(C) David F. Heathfield and Sören Wibe 1987

Softcover reprint of the hardcover 1st edition 1987

All rights reserved. No reproduction, copy or transmission of this publication may be made without written permission.

No paragraph of this publication may be reproduced, copied or transmitted save with written permission or in accordance with the provisions of the Copyright Act 1956 (as amended).

Any person who does any unauthorised act in relation to this publication may be liable to criminal prosecution and civil claims for damages.

First published 1987

Published by

MACMILLAN EDUCATION LTD

Houndmills, Basingstoke, Hampshire RG21 2XS

and London

Companies and representatives

throughout the world

British Library Cataloguing in Publication Data

Heathfield, David F.

An introduction to cost and production functions.

1. Production functions (Economic theory)

I. Title II. Wibe, Sören

$338^{\prime} .001$ HB241

ISBN 978-0-333-41607-5

DOI 10.1007/978-1-349-18721-8

ISBN 978-1-349-18721-8 (eBook) 


\section{Contents}

Preface ix

Symbols xii

Abbreviations xiv

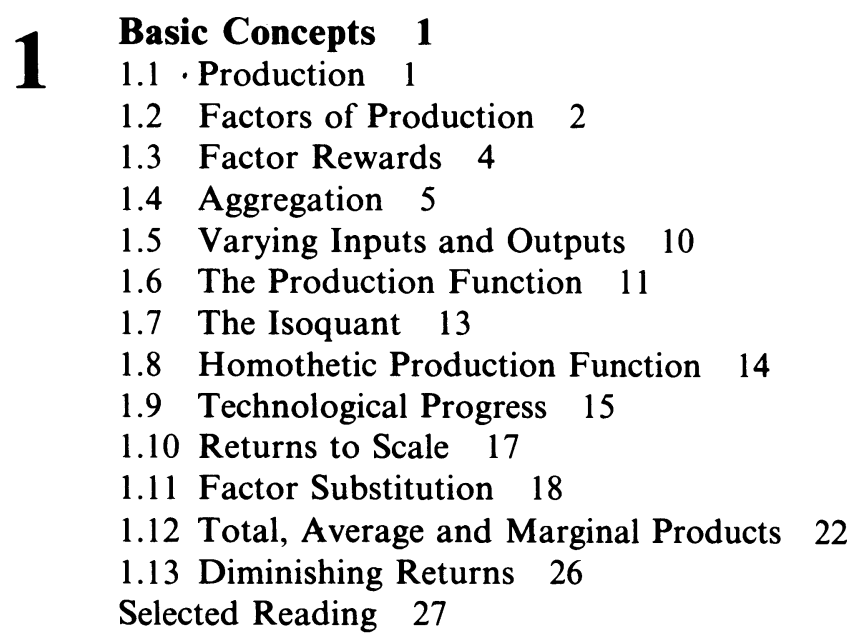

2 Cost Functions and the Theory of the Firm 28

2.1 Optimisation 28

2.2 The Isocost line 28 
2.3 The Cost-minimising Choice of Technology 30

2.4 Cost-minimising Choice of Technology in the Short Run 33

2.5 Cost Functions in the Long Run 34

2.6 Cost Functions in the Short Run 38

2.7 The Relation Between Long- and Short-run Cost Curves 40

2.8 Factor Demand in the Long and Short Run 41

2.9 Determination of Output Level 42

2.10 Output Determination in Perfect Competition 43

2.11 Output Determination in a Monopolistic Market 47

Appendix: Returns to Scale, Imperfect Markets and the Second Order Conditions for a Maximum 48 Selected Reading 52

3 Elasticity, Efficiency and the Theory of the Firm 53

3.1 Introduction 53

3.2 Output and Substitution Effects 53

3.3 The Elasticity of Scale 55

3.4 The Elasticity of Scale and Shape of the Cost Functions 56

3.5 The Elasticity of Substitution 58

3.6 Factor Demand and Elasticity of Substitution 60

3.7 Putty-Clay Technology 63

3.8 Putty-Clay and Frontier Production Functions 64

3.9 Long- and Short-run Industrial Supply Curves 69 Appendix 70

The Elasticity of Substitution in the General $n$-factor case 70

The relation between the elasticity of substitution and the price elasticities in the general case 72

The elasticity of substitution and the cost functions 73 Expressing the elasticity of substitution in terms of the partial derivatives of the production function 73 Selected Reading 74

\section{The Cobb-Douglas Function 76}

4.1 Introduction 76

4.2 Cobb-Douglas Isoquants 77 
4.3 Short-run Total, Average and Marginal Product Curves for Cobb-Douglas 78

4.4 The Cobb-Douglas Elasticity of Substitution 80

4.5 Returns to Scale and the Cobb-Douglas 81

4.6 Cobb-Douglas Factor Demand Functions 82

4.7 Cobb-Douglas Cost Functions 84

4.8 The Adding-up Problem 86

4.9 The Aggregate Cobb-Douglas Function 89

Selected Reading 91

\section{The CES Function 92}

5.1 Generalising the Cobb-Douglas 92

5.2 The Elasticity of Substitution of the CES 94

5.3 The CES Isoquants 95

5.4 Returns to Scale 97

5.5 Short-run Total, Average and Marginal Products for the CES 98

5.6 The CES Factor Demand Functions 100

5.7 CES Cost Functions 102

Selected Reading 104

6 The Translog Function 105

6.1 Introduction 105

6.2 The Elasticity of Scale and the Translog 107

6.3 The Translog Isoquant 109

6.4 Short-run Product Curves for the Translog 109

6.5 The Translog Cost Function 110

6.6 The Elasticity of Substitution of the Translog 112 Appendix: Some other functional forms 112

Selected Reading 117

\section{Technological Progress 118}

7.1 Introduction 118

7.2 Product Innovation and Process Innovation 118

7.3 Embodied and Disembodied Technological Progress 119

7.4 Neutrality of Technological Progress 120

7.5 Some Functional Forms 122

7.6 Learning by Doing 127

7.7 Research and Development 128 
7.8 Patents 129

7.9 Technological Progress and Economic Growth 130

7.10 Summary and Conclusions 133

8 From Firms to Industry: the Johansen Production Model 134

8.1 Introduction 134

8.2 Ex Ante Functions at Micro and Industry Levels 135

8.3 The Ex Post Micro Function 137

8.4 The Ex Post Industry Production Function 138

8.5 Competitive Markets and the Bang-Bang Solution 139

8.6 The Short-run Industry Function Obtained Through a Competitive Market 141

8.7 Construction of an Isoquant - an Example 142

8.8 The Elasticity of Scale 147

8.9 The Elasticity of Substitution 149

Appendix: The Houthakker Model 150

Selected Reading 152

\section{Empirical Work on Production Functions 153}

9.1 Introduction 153

9.2 The Econometric Approach 154

9.3 Stochastic Equations 155

9.4 The Error Structure 156

9.5 Simultaneous Equation Systems 159

9.6 Estimating the Translog Production Function 167

9.7 The Engineering Approach 170

9.8 The Formal Structure of Engineering Analysis 170

9.9 An Illustrative Example of Engineering Functions 172

9.10 Statistical Estimation from Engineering Data 176

9.11 Merits and Drawbacks of the Engineering Approach 177

9.12 Empirical Engineering Production Functions 178

9.13 Empirical Best Practice Studies 179

9.14 Empirical Short-run Macro Functions 180

Selected Reading 182 


\section{Authors' Preface}

There can be little doubt that production functions, and their associated cost functions, form an integral part of an enormous range of economic theory. In microeconomics, production functions underlie the supply side of markets, generate production possibility frontiers, offer an explanation of income distribution and yield factor demand functions. Production functions are also central to the theory of economic growth and to investigations into the rate of technological progress. In international trade, production functions are used to provide a rationale for product and factor movements across national boundaries. In macroeconomics, production functions lie behind aggregate supply functions, aggregate labour demand functions and form the link between output and the consequent employment. Even the demand side can make use of production functions. The functional forms used for utility functions are often 'borrowed' from production theory. Indeed the production model has been transferred wholesale to model 'demand'.

It is clear from this somewhat impressive list that a knowledge of production functions is a useful if not essential part of being an economist.

The kind of production function most widely used is the so-called 'neoclassical' production function. Neoclassical functions can take a host of forms (as we shall see in the following chapters) but they all have three fundamental characteristics. First they represent ways in which labour, capital and land can be combined to produce goods. Second, they assume that capital is a separate, independent input 


\section{Authors' Preface}

directly comparable with labour and land. And third, they focus attention on the production possibilities and decisions within processes, firms or industries.

Many of the results which spring from these functions, when applied to the various aspects of economics listed above, rely on these implicit assumptions. They are not without their critics.

A slightly different approach derives from general equilibrium models and focuses attention on inter-firm relationships of production. The Leontief production model is perhaps the best known example of this approach. Each sector uses capital and labour but also needs inputs from other sectors. The 'Food, Drink and Tobacco' sector, for example, buys materials from Agriculture, and Agriculture buys from Chemicals and so on. There is no substitution among inputs and so the inputs into each sector are usually assumed to be determined simply by the output of that sector. This approach is known as input-output analysis and concentrates on the interdependence of industries, firms and processes rather than choice of techniques within an industry, firm or process.

The input-output approach is widely used in planning models where the 'balance' among industries is important. And input-output is largely regarded as an alternative to neoclassical functions rather than a contradiction of them.

A third approach, the 'classical' production model, does however directly contradict the 'neoclassical' model. This approach is like the input-output approach in that attention is focused on inter-industry relations. In this classical model, however, one of the sectors produces capital goods-capital is explicitly recognised as a produced input. Whereas land and labour are 'original' inputs, capital is also an output. This modification is sufficient to render many of the 'standard' results of neoclassical production theory invalid. It is no longer unambiguously true, for example, that increasing the interest rate vis-à-vis the wage rate will induce capital saving. Sraffa (1972) has shown that it is possible for a particular man/machine combination to be used at low rates of interest, fall into disuse as interest rates rise and then, as they rise still further, switch back into operation again. This result would not be possible in a neoclassical model of production. As interest rate rises less and less capital is used and more and more labour so that the capital-labour ratio continues to fall for all increases in interest rate.

According to this classical model it is simply not possible simul- 
taneously to determine factor and product prices as it is in the neoclassical world. It is necessary first to specify the wage/interest ratio and from this the choice of technique and product prices are found.

The so-called 'capital controversy' has been widely covered in the literature (Harcourt (1972), Kregel (1976) and cf. Bliss (1975)) and is rather beyond the scope of an introductory text such as this. Whatever merits or flaws the neoclassical production model may have it is indisputably the dominant model and economists require to have some understanding of it.

It is not our intention here to stress the controversies or to offer a comprehensive account of the various applications of production theory. Our aim is simply to bring together in one volume the principal neoclassical approaches to production and to compare and contrast their properties.

Production functions imply particular cost functions, often the 'self-dual' of the production function. These cost functions are sometimes of interest in their own right but are sometimes used as more tractable alternatives to production functions. For these reasons we introduce, where appropriate, the cost functions associated with each production function. We have tried to keep the inevitable mathematics to a fairly simple level and have consigned the more esoteric points to appendices which can be ignored by the general reader. Each chapter begins with fairly simple concepts and becomes progressively more difficult. Some students may find that the early parts of the chapters are all that is required.

There are two general chapters: one on estimating production functions and one on technological progress. These are included merely to indicate to the student some of the difficulties and some possible solutions which have been discussed in the literature.

We have, in short, tried to provide a rigorous yet accessible introduction to the principal aspects of cost and production functions.

David F. Heathfield

Sören Wibe 


\section{Symbols}

The following symbols are used throughout this book:

$q=$ Quantity of firm output.

$Q=$ Quantity of industry output.

$v_{i}, \ldots, v_{n}=$ Firm inputs No $1, \ldots, n$.

$V_{1}, \ldots, V_{n}=$ Industry input.

$K=$ Quantity capital (same for firm and industry).

$L=$ Quantity labour (same for firm and industry).

$E=$ Quantity energy (same for firm and industry)

$t=$ time.

$P=$ Prices of output (same for firm and industry).

$P_{1}, \ldots, P_{n}=$ Prices of inputs.

$\pi=$ Profits.

$\varepsilon=$ Elasticity of scale.

$\varepsilon_{\mathrm{c}}=$ Elasticity of cost (with respect to production level).

$\sigma=$ Elasticity of substitution (in a two-factor production model)

$\sigma_{r s}=$ Allen partial elasticity of substitution between inputs $r$ and $s$.

$E_{j}=$ Price elasticity of demand for factor $j$.

$S_{j}=$ Cost-share for factor $j$.

$E_{i j}=$ Cross-price elasticity of demand for factor $i$.

$C=$ (Total) cost of factors.

$f_{i}=$ partial derivative of function $f($ ) w.r.t. factor $i$

$\xi_{j}=$ Input coefficient for factor $j$ (i.e. input per unit of output)

$U=$ Error term

$A, B, a, b, \alpha, \beta, \gamma, \lambda, \theta, \delta$ are used as parameters. 
A dot (.) above a symbol (e.g. $K$ ) indicates rate of growth.

A line above a symbol (e.g. $\bar{q}$ ) indicates any arbitrarily fixed level. A hat or a star above a symbol (e.g. $\hat{q}$ or $\left.{ }^{*}\right)$ indicates some special level (e.g. the cost-minimising level). 


\section{Abbreviations}

The following abbreviations are used throughout this book.

$\mathrm{SR}=$ Short Run

$\mathrm{LR}=$ Long Run

$\mathrm{TC}=$ Total Cost

$\mathrm{FC}=$ Fixed Cost

$\mathrm{VC}=$ Variable Cost

$\mathrm{MC}=$ Marginal Cost

$\mathrm{AC}=$ Average Cost

ATC $=$ Average Total Cost $(=\mathrm{AC})$

$\mathrm{AVC}=$ Average Variable Cost

$\mathrm{AFC}=$ Average Fixed Cost

LRAC $=$ Long Run Average Cost

SRAC $=$ Short Run Average Cost

$\mathrm{TR}=$ Total Revenue

$M R=$ Marginal Revenue

$\mathrm{AR}=$ Average Revenue

$\mathrm{TP}=$ Total Product

$\mathrm{AP}=$ Average Product

MP $=$ Marginal Product

RTS $=$ Returns to Scale

CRTS $=$ Constant Returns to Scale 
DRTS $=$ Decreasing Returns to Scale

IRTS = Increasing Returns to Scale

$\mathrm{CD}=$ Cobb-Douglas (Production Function)

$\mathrm{CES}=$ Constant Elasticity of Substitution (Production Function) 